\title{
HORACIO Y LAS MUSAS
}

\author{
Maria Délia Buisel de Sequeiros \\ Universidad Nacional de La Plata
}

\section{Delimitación del tema}

La significación de las Musas en la poesia horaciana se entreteje con la de otras divinidades vinculadas a la poesía como Baco, Apolo y en menor escala Orfeo y Anfión, comportando el conjunto, unido al tema del poeta (poeta y vates) y la poesía, una compleja constelación sobre la teoría poética de Horacio.

El tema se relaciona además con la actitud religiosa del autor, el posible itinerario de la misma ${ }^{1}$, las influencias epicúreas ${ }^{2}$ y estoicas que interfieren, encausan 0 favorecen esa trayectoria conformando una quaestio disputata apasionante y abierta.

Horacio emplea tanto Musa como Camena, equivalente itálico de la figura griega, usado antes por Ennio, aunque el segundo término es menos frecuente que el helénico; una sola vez aparece Piplea.

También Musa y Camena aparecen como metonimia de carmen, cantus 0 melos $^{3}$, pero nuestro objetivo es la Musa (o las Musas) como divinidad "quae poeticae et musicae et ceteris liberalium artium desciplinis praest", según presentación de D. Bo $(B o, 1966, \text { t. II, p. } 62-3)^{4}$, 10 que todavía resulta insuficiente como intentaremos demostrar y precisar.

Horacio es el poeta augusteo en quien la realidad del fenómeno poético se presenta con un alto grado de complejidad y como fruto de varias divinidades que no interfieren una en la esfera de la otra, aunque son cercanamente linderas, expresado esto con un lenguaje lírico pleno de imágenes en las Odas, o con un sermo quotidianus más racionalizado en Sátiras y en Ars poetica, donde se

1. Tema bien planteado, aunque no en todas sus posibilidades por H. Oppermann (Oppermann, 1972, p. 167-182).

2. Tema tratado por K. Buechner (Buechner, 1968, p. 457-469) al plantear la doble perspectiva, politica e individual de la poesia de Horacio y el valor limitado de un sistema racional como el epicúreo para abarcar ambas lineas. Precisamente las Musas sobrepasan los limites estrechos de esta filosofía, lo que Buechner ejemplifica muy bien con ellas.

Sin embargo en otra comunicación posterior (Buectiner, 1970, p. 11) restringe la objetividad de las Musas, asI afirma "Horace ne parait pas procéder des Muses, mais d'un pouvoir transfigurant localisé dans son esprit lui-même".

3. Camena como metonimia de carmen aparece en Odas I, 12, 39 cuando Horacio anuncia que enaltecerá a Régulo, Escauros, Paulo y Fabricio, viejos héroes romanos con su

$$
\begin{aligned}
& \text { gratus insigni referam Camena } \\
& \text { o en Odas I, 17, 13-14 } \\
& \text { Di mi tuentur dis pietas mea } \\
& \text { et Musa cordi est. }
\end{aligned}
$$

Dominicus Bo (Bo, 1966, t. II, p. 62-63) añade en su Lexicon, Oda II, 1, 19, Epist. I, 8, 2, 8át. II, 6, 17 donde rechazamos Musa como metonimia.

4. Esta observación sobre Bo (op. cit.) vale para los artículos Musa y Camena, a los que añadimos los que precisan los nombres de cada Musa. 
distinguen elementos y fases del proceso poético como no lo había hecho ninguno antes de êl.

En otra comunicación anterior (Buisel, 1990) ${ }^{5}$ hemos estudiado la polisemia de Baco en Horacio; con un alto grado de originalidad Baco aparece explicitamente 0 aludido con algún símbolo en Odas (I, 1; II, 19; III, 25) como díos de la poesía, ubicándose antes de Apolo, en el acto inicial del proceso poético; en el instante de la inspiración. Baco le comunica al poeta el entusiasmo que lo enajena y lo aparta del mundo vulgar arrebatándolo a un estado de éxtasis con una locura que no lo daña para que cante en III, 25 la inserción de Augusto en la gloria olímpica.

Apolo aparece al final coronando al poeta por la perfección de la obra cumplida y como dispensador del ars y del renombre alcanzado y perdurable.

¿Cómo y dónde ubicamos las Musas? ¿Existe el mismo grado de relación entre ellas y el poeta, que con Baco y Apolo? ¿Es la Musa, todas las Musas o ciertas Musas las que se vinculan con el poeta? ¿Difiere la teofanía de la Musa en Sátiras, Odas y Epístolas? racional.

Comenzaremos por la pregunta final que nos permite un análisis más

\section{La MUSA en las SÁtiRas}

Omitimos Sát. II, 3, 105 porque Musa es una metonimia por arte 0 poesía. Las demás menciones son escasas, pero no menos interesantes.

En Sát. I, 5, 53 la Musa invocada para una batalla hace pensar en un comienzo épico, pero se trata sólo de una pelea entre bufones, degradando con el recurso de una parodia irreverente la habitual evocación de la epopeya

\section{nunc mihi paucis}

Sarmentis scurrae pugnam Messique Cicirri,

Musa, velim memores.

En Sát. I, 10, 45 aparecen las Camenas dispensando a Virgilio su poesía bucólica en la línea helénica de la inspiración poética,

Vergilio adnuerunt gaudentes rure Camenae.

pero con una restricción: las Musas sólo consienten una especie lírica: la pastoral, porque ellas se gozan con el campo; restricción que conviene a la partición de campos poéticos dada en esta composición donde Horacio se reserva para sí la sátira, un genus mixtum ${ }^{6}$, por él considerado de nivel inferior al lírico, épico 0 trágico caracterizado con precisión como pedestris en Sát. II, 6, 17; la expresión se verifica en un contexto más lírico que satírico, pues Horacio rezuma felicidad por la finca sabina, don de Mecenas; a Mercurio, su particular dios protector, le pide que

5. Forma parte de una serie sobre el acontecer poético en Horacio.

6. Cada autor se replantea en su poética los límites de su género; la Musa pedestre y las Musas líricas son símbolos de esa ruptura y recomposición de géneros y especies (cf. Buisel, 1992, p. 1-11). 
sea custodia de su ganado y de si mismo, que los conserve "pingues", excepto su "ingenium"7; alli desea retirarse 10 más pronto posible abandonando Roma para dedicarse al otium y a la poesia

\section{quid prius inlustrem saturis musaque pedestri?}

Con este adjetivo que comporta la idea de inferioridad 0 bajeza entendiendo la sátira como poesia pedestre, baja o humilde en relación a los otros géneros, cercana a la prosa $\left(\pi \varepsilon \zeta \sigma^{\prime} s\right)$, no hay mayormente problema; sí con el vocablo Musa, visto en general como metonimia ${ }^{8}$ por poesia satírica, pero "saturis" ya está presente en el mismo sintagma, por lo que descartamos una hendiade; a la luz de Sát. I, 4, 39-449 y de la plegaria a Mercurio en el mismo texto (Sát. II, 6, 515), creemos en la musa como dea aunque sea dadora de un nivel conversacional de poesía, opuesta a las sublimidades de los géneros mayores, pero diosa al fin, porque Horacio sabe perfectamente que este sermo no es sólo fruto del ars, o sea de la $\tau \hat{\chi} \chi v \eta$ poética, sino también del ingenium 0 talento, don de una esfera trascendente que bien podemos llamar Musa por su caracter personal.

Mencioné Sát. I, 4, 39-44, dado que allí Horacio distingue entre poeta satírico y el que se dedica a un género mayor no especificado. Al satírico - en este caso Horacio mismo - no le corresponde el nombre de poeta, por lo que él se excluye de tal gremio; el vocablo debe reservarse para quien posee "ingenium, mens divinior atque os magna sonatarum", lo que puede valer para las especies más elevadas de la lírica, pero fundamentalmente para la épica y la tragedia.

7. Horacio emplea "pingues" en clara alusión al prólogo de los AltIA (v. 22-24) de Calímaco (ed. Pfeiffer, 1949, p. 5).

'A

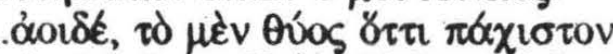

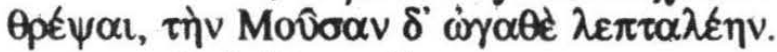

Apolo licio me dijo:

..Cantor, la ofrenda lo más gorda posible

cébala, pero la Musa, on bueno, delicada.

8. E. Turolla (Turolla, 1963, p. 374) traduce Musa pedestri por la perifrasis "poesia cosi vicina al palare umile e basso"; F. Villeneuve (Villeneuve, 1966, p. 192) por "dans mes satires et dans leur vers familier"; ambos comentaristas rechazan aqui Musa como dea; para G. Lleberg (Lieberg, 1977, p. 1970) es una metáfora del género satírico próximo a la prosa, perp no hay que olvidar la idea de la que deriva este uso: "un poème particulier, la nature d'un poète, oư un genre poètique peuvent être appelés par les noms de ces divinités seulement parce qu'ils sont conçus comme fruits ou don de l'inspiration donnée par les Muses". Menos dudas le ofrece (op. cit., p. 969) "mens divinior" que hace derivar de Demócrito

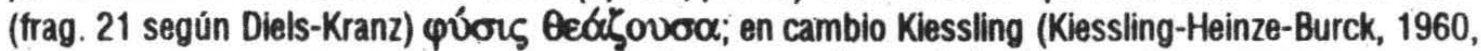

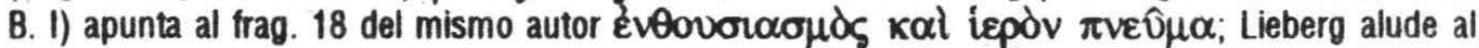
ingenium o indole del poeta, y sólo con el adjetivo a la Musa; Kiessling en cambio apunta con el sustantivo mens más bien a la Musa misma.

9. Horacio: Sát. I, 4, 39-44

Primum ego me illorum, dederim quibus esse poetis, excerpam numero; neque enim concludere versum dixeris esse satis, neque, siqui escribat uti nos sermoni propiora, putes hunc esse poetam. Ingenium cui sit, cui mens divinior atque os magna sonatarum, des nominis huius honorem. 
Concedamos que la sátira no requiere "os magna sonatarum" (voz para hacer resonar grandes temas en alto estilo), pero exige unido al ars, talento 0 ingenium, posesión de la que Horacio con toda picardia se sabe conciente.

El ingenium es hijo de la Musa, no mencionada aqul con tal nombre, sino aludida más impersonalmente en "mens divinior" con el adjetivo; dicha expresión no comporta una exclusión lisa y llana de una divinidad inspiradora; con "mens" Horacio apunta al poeta mismo y con "divinior" a una realidad que lo trasciende, aunque es posible que todo el sintagma aluda a esta realidad.

Horacio es poeta estrictamente cuidadoso de las atribuciones; observemos que "divinior" está en grado comparativo sin complemento de comparación; entendemos entonces un término omitido que implica comparar genera maiora (divinior) con la sátira a la que le correspondería un positivo "divina"; 0 interpretar el adjetivo en un grado de intensidad más alto sin término explicitable; cualquiera de ambas - aunque me inclino por la primera dado el contexto comporta un adjetivo en grado positivo como si para la sátira se precisase sólo de una mens divina, pero sin elevación o sublimidad de tono y estilo; en suma "divinior" supone la inspiración de una divinidad proveniente de una esfera superior que en Sát. II, 6, 17 tiene nombre y estricta caracterización "Musa pedestri".

\section{LA MUSA EN LAS OdAS}

La "mens divinior" de la Sátiras desemboca en la Musa lírica de las Odas y las clave para la intelección de éstas; alli Horacio trabaja a la perfección con un lenguaje rico en imágenes y conceptos todos los aspectos del fenómeno poético.

A esto se suma el contexto histórico que contribuye a una valoración del antiguo pensamiento e imaginería griegos; la época augustea reivindica la significación fontal de la poesía arcaica y clásica sin el desfonde religioso producido por el racionalismo de las diversas escuelas filosóficas o el embate helenístico ${ }^{10}$. Virgilio y Horacio testimonian esa actitud, pues su revaloración del mito, la poesia y

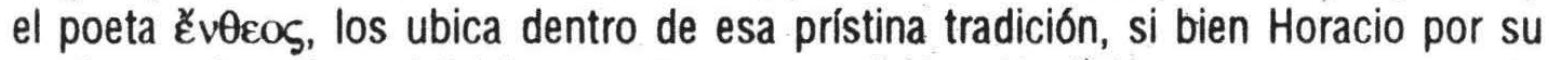
confeso epicureísmo inicial presente sus convicciones relígiosas como una vexata quaestio que sigue vigente.

Es tan multiforme la presencia de la(s) Musa(s) en Horacio que cuesta ordenar su análisis, por eso las trataremos según su aparición en las Odas ya que este orden implica de por si un crecimiento de los valores que el poeta les reconoce según la tradición y por otro, lo que él descubre profundizando a través de su figura el fenómeno poético.

Por una cuestión de método indagaremos primero la significación de las Musas con nombre y luego la de la(s) Musa(s) en general. 


\section{Primera Parte}

\section{Individuación de la Musa}

\section{Euterpe y Polyhymnia}

Oda I, 1: Como culminación del extenso y elaborado priamel ${ }^{11}$ de las vocaciones humanas, aparece la del poeta docto (v. 29-34) en contraposición y recusatio a las ya enumeradas ${ }^{12}$; por la inspiración dionisíaca - no hablamos del vino sino de la mirada extática de Dionysos -, Horacio puede unirse, como los héroes, a los celestiales, y compartir el reino de las musas ligeras y de los sátiros, pero la acción y el efecto de este $\pi v \varepsilon \hat{v} \mu \alpha$ sacro está condicionado a la continuidad de la música de Euterpe y Polyhymnia ${ }^{13}$; en cuanto a la función de las mismas no todos los comentaristas coinciden, ¿qué limites tiene esta restricción y en qué campo opera?

Por empezar, no tienen las musas en este texto la primacía del soplo inspiratorio - eso es atribución de Baco simbolizado en la hiedra -, ni la perfección de la obra lograda, don apolíneo como se verá en otras odas.

Quedan en el medio estos dos nombres significativos; tampoco la división alejandrina de las Musas como presidiendo otras esferas del pensamiento resulta suficiente; Horacio con seguridad las conoce, pero no le bastan.

Conviene rastrear hasta las Musas hesiódicas, primigenias y verdaderas teofanías, cuyo nombre se impone como único atributo, para que el poeta lo devele. Euterpe es la del goce y el encanto armonioso, Polyhymnia, la de los múltiples himnos; la primera en relación con la flauta, que Syndikus (Syndikus, 1989, p. 2337) ve como una alusión a los ecos elevados y cercanos a la lírica coral de muchas de sus poesias ${ }^{14}$, la segunda con la lira, y en particular con el "Lesboum barbiton" (sustantivo más solemne que lyra o cithara), en clara alusión al género lirico y a los paradigmas del mismo: Alceo y Safo. En la referencia arcaica está anticipada la

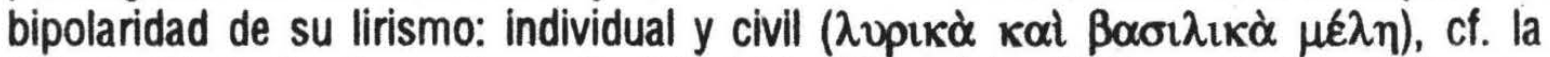
Oda I, 32 dedicada a Alceo. R. Kilpatrick (Kilpatrick, 1969, p. 234) señala una variante $^{15}$ : la flauta apunta a una tonalidad alegre y la lira a una seria. P. Connor (Connor, 1981, p. 1637) descubre una veta del realismo horaciano porque estos

11. Muy pormenorizado el estudio de W. Race (Race, 1982, p. 122-3), donde analiza el priamel de Oda I, 1.

12. Horacio: Oda I, 1, 29-34
Me doctarum hederae praemia frontium dis miscent superis, me gelidum nemus Nympharumque leves cum Satyris chori secernunt populo, si neque tibias Euterpe cohibet nec Polyhymnia Lesboum refugit tendere barbiton.

13. En Ars Poetica, 202-205 vincula la flauta como acompañante del coro trágico, pero en Odas las referencias son puramente liricas.

14. Añade sin dar referencia, que tal vez Horacio retome una relación griega tradicional.

15. Euterpe with the tibiae and Polyhymnia with the Lesboum barbiton may represent the variety of the modes of lyric, perhaps here the joyous and the serious" 
versos indicarian la instantaneidad de la propia inspiración y su tenuidad, es decir su calidad lírica ${ }^{16}$.

G. Lieberg (Lieberg, 1977, p. 966) interpreta literalmente la continuidad del son de las Musas como condición para ingresar en la esfera divina; sin excluir esta interpretación creemos que esta oda anticipa por su carácter programático ${ }^{17}$. en la doble nominación, la diversidad de las especies líricas que desplegará Horacio en Odas I-III.

De entrada, el poeta anticipa un rasgo propio en su ahondamiento de la Musă, deja a un lado las particiones helenísticas, y en la linea hesiódica de las Musas como nueve nombres de la poesía, Horacio se dedica a develar una especie lírica o un sesgo de su lírica en el nombre de cada Musa.

Clío

Oda I, 12: Muestra otra musa individualizada

Quem virum aut heroa lyra vel acri

tibia sumis celebrare, Clio? (v. 1-2)

Su nombre se vincula con el verbo $\kappa \lambda \varepsilon i ́ \varepsilon ı$ que indica la celebración de la gloria heroica, lo que se rubrica con el celebrare del v. 2. Una de las especies líricas de estilo elevado o sublime, cercana a la épica es el epinicio (canto de alabanza por una victoria); como variante de este tipo pindárico, Horacio elige la glorificación de Augusto como culminación de una totalidad iniciada en Júpiter, seguida por dioses y héroes del mito y por los paradigmas de la historia romana ${ }^{18}$, cerrándose con la exaltación del César nicéforo, segundo analógico del padre de los dioses en una de las odas más perfectas de la $\beta \alpha \sigma ı \lambda ı$ ıò $\mu \varepsilon \hat{\varepsilon} \eta$. Con el mismo recurso de III, 4 , Horacio requiere a la Musa un poema que se presenta como entonado por ella; si el poeta celebra y glorifica es porque Clio lo hace primero.

\section{Callope}

Tal vez la oda clave para la comprensión del poemario interno formado por las seis odas romanas.

A Calíope le requiere Horacio un "longum melos",

16. "He has too realistic a sense of tenuousness of his own inspiration."

17. Carácter programático heredado de la tradición de los poemarios y propio de las colecciones de Virgilio o de los eleglacos. Otro rasgo programático destacado por Nisbet (Nisbet, 1970, p. 14) es la mención genérica o individualizada de las Musas en los poemas de dedicación; extraña que un comentario tan excelente no diga más de ambas Musas; remite a la exégesis sobre Melpómene (op. ct., p. 282-3) indicando que la división en provincias helenisticas no parece ser la empleada por Horacio, sino más bien habría que indagar por la etimología.

18. Cuando Horacio pasa a la historia romana Clio se transforma en la "insigni Camena" (v. 39). Aquí el atributo está en estrecha correlación con "magna anima" de Paulo Emilio y con las demás acciones de los héroes nombrados. 
Descende caelo et dic age tibia

regina longum Calliope melos,

seu voce nunc mavis acuta

seu fidibus citharave Phoebi.

no en cuanto musa épica; ya Alkman (14a y 27), Estesícoro (63 y 101) Safo (127 y 128), Píndaro (Nem. 3, 1) invocan a Calíope con toda propiedad lírica. No hay duda de que "longum" es referencia con sus ochenta versos a la oda más extensa de I-III.

¿Por qué Caliope? Esta oda despliega hasta ella, las mayores virtualidades de una musa o de las musas en general vistas a través de una sola.

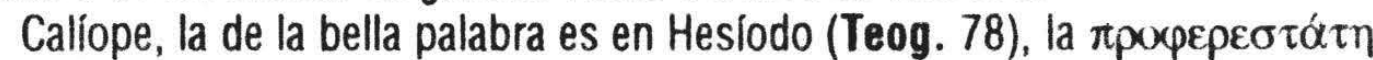
$\alpha \pi \alpha \sigma \varepsilon \omega v$, que resume en el suyo, los nombres de todas sus hermanas; si Clío intenta celebrar en forma deliberativa con la lira o la flauta, Callope desciende con impetu para su melodía, añadiendo su voz aguda a la flauta o a la cítara.

El delirio que comunica al poeta es "amabilis" (el de Baco en II, 19 más enajenante y temible) y lo tranisporta al prado de las Piérides donde todo se transforma prodigiosamente.

El episodio fabuloso de la infancia con las palomas que lo cubren de laurel y mirto ${ }^{19}$, mientras duerme a salvo de osos y víboras se debe a ta protección de las Musas, ya que es un niño "non sine dis". En I, 17, 13-14 recuerda que "di me tuentur, dis pietas mea / et Musa cordi est", en una expresión más general que la enunciada taxativamente en v. 21 ss.:

Vester, Camenae, vester.....

donde marca la posesión de Horacio niño y hombre por las Musas en todo lugar y tiempo de su vida, extendiendo este patronato a esferas no poéticas, así su entrega a las Camenas lo salvó en Philippos, en su finca de la caída de un árbol y en el Adriático de un naufragio; esto es mucho más que el don de la poesía, es una consecuencia de este don, evidenciando como algo nuevo una tierna y devota intimidad entre ellas y él.

Por otra parte, asI como las musas hesiódicas y pindáricas extienden la esfera de su benevolencia a reyes y gobernantes insuflándoles el sentido de la justicia, las Camenas horacianas recrean al gran César y le conceden gozosas su "lene consilium" no para ganar la guerra sino para gobernar en paz con moderación y templanza (vim temperatam, v. 66).

Sólo la musa omnicomprehensiva, Calíope ${ }^{20}$, podrá asumir en sí misma la polivalencia de todas las funciones fraternas y en nivel político donde la comunidad toda se beneficia hasta su último resquicio por la mediación de Augusto asistido por el don de la prudencia política.

19. Vemos en el laurel y el mirto también una alusión a los temas apolíneos y civiles unidos a los de la lírica amorosa de Horacio.

20. E. Fraenkel (Fraenkel, 1966, p. 281, n. 1) observa que no hay fractura entre Caliope en singular y Camenae en plural, ya que es variante tradicional desde los tempranos modelos griegos obedientes a viejas creencias y formas de devoción; en los romanos se trataría sólo de "purely artistic grounds"; en realidad, como hemos visto, la representación de Caliope es verdaderamente significativa. 
Es inexplicable que H. P. Syndikus (op. cit., II, p. 52) considere intercambiables a Clío y a Calíope y elegidas sólo por un motivo de eufonía ${ }^{21}$.

No olvidemos que la segunda parte de la oda refiere la Titanomaquia como ejemplo de la fuerza ciega derrotada por el "consilium" racional y temperado, episodio mítico aleccionador de la historia presente y futura, episodio del pasado que sólo la(s) hija(s) de Mnemosyne, la altamente memoriosa, podía inspirar, porque del antaño de los dioses, de lo que fue, sólo ellas pueden revelar y cantar.

Horacio entona en III, 4 un himno de contenidos más elevados aún que I, 12 , pues la dispensación comunitaria de la justicia y la $\operatorname{paz}^{22}$ se añade al don de la música y la celebración.

\section{Melpomene}

Muy significativamente aparece en tres odas con un contenido fundamental acorde con su valor etimológico: el verbo $\mu € \lambda \pi \omega$ se traduce por cantar, celebrar, hacer resonar un canto; tiene la misma ralz de $\mu \varepsilon \hat{\lambda}$ os, cuyo plural $\mu \varepsilon \hat{\lambda} \eta$ es la poesía lírica por oposición a la épica y la dramática; el singular en una de sus acepciones, es canto con acompañamiento musical y con medida, cadencia y

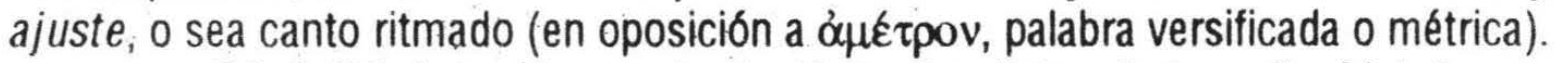

Oda I, 24: Antes de su adscripción racionalista a la tragedia, Melpómene es la musa lírica por excelencia, voz límpida y cítara son sus atributos, y en carácter de moduladora de un canto fúnebre, primero incorporado a la colección, es invocada por el poeta para que le enseñe un $\theta p \hat{v}$ os, a medio camino entre él epicedio y la consolatio

cantus, Melpomene, cui liquidam pater
vocem cum cithara dedit. (v. 2-4)

Melpómene es invocada para enseñar "lugubris cantus" en tanto que dispensadora de los ritmos justos, es decir, concordes con cada tema, en este caso, el funerario o las variantes elegíacas del dolor.

Oda III, 30: En la clausura de I-III, Melpómene corona al poeta con el laurel de Delfos, signo de la obra perfecta y lograda; esta aparición va mucho más

21. "Die Wahl gerade der Muse Kalliope ist wohl eher dem schoenen Klang des Wortes und dem usus griechischer lyriker zuzuschrieben als einem inhaltlichen Grund." En la nota 19 de la misma página agrega: "Klio (I, 12, 2), Melpomene (I, 24, 3; III, 30, 16; IV, 3, 1), Thalia (IV, 6, 25) alle ohne inhalttiche Differenzierung."

Tampoco nada dicen de Calíope ni V. Cremona (Cremona, 1982, p. 222-238) ni Ch. Witke (Witke, 1983, p. 47-57) que ven a Caliope como un puente para enlazar el final de III, 3 con III, 4 lo que es verdad, pero resulta insuficiente.

22. G. Lieberg (op. cit. p. 963-4) resalta el valor filosófico del don moderador de las Musas honradas especialmente por pitagóricos, platónicos y estoicos (cf. tb. P. Boyancé, 1937, III parte, p. 229-351) puesto que la vis temperata" es participación del $\lambda$ ópos universal, de la ratio; causa profunda del universo y de la vida humana. El mismo Boyancé en otro estudio más breve (Boyancé, 1955, p. 48-64) es aún más taxativo; las Musas de III, 4 representan la sabiduría filosófica y sólo en segundo término, las letras y las artes. 
lejos de I, 24, pues si bien las Musas dependen voluntariamente de Apolo, que las instruye como su maestro, es con su consentimiento que orna al poeta con la misma guirnalda del dios, sostenida por los exponentes máximos en cada género.

Llegado a III, 30 el poeta retrotrae la mirada y recapitula la complejidad de temas, tonos, metros, ritmos, tratamientos, etc., en una sola imagen: la de Melpómene, quien asume todas las especies de su lírica: amorosa, amical, doliente, convivial, parenética, hímnica, civil, etc. en una profundización acabada de su nombre, la que modula todos los ritmos, particularmente los eolios, de los que Horacio ha devenido el princeps romano. Bien dice Fraenkel (Fraenkel, 1966, p. 306) que "Melpomene here means Muse of my lyrics".

Horacio devuelve a Melpómene agradecido la excelencia (superbia) lograda por los méritos poéticos ${ }^{23}$ y sólo por ese reconocimiento raigal del don que gratuitamente detenta, puede pedir libremente que la musa lo corone de buen grado como patrona de su nueva lírica "Italos modos" (v. 13-14)

Sume superbiam

quaesitam meritis et mihi Delphica

lauro cinge volens, Melpomene, comam. (v. 14-16)

En suma, la Melpómene de III, 30 ha recogido la armonía y los sones de la flauta y la lira que prodigaron Euterpe y Polyhymnia $(I, 1)$ en una altísima recapitulatio.

Oda IV, 3: Para reafirmar el natural patronato de Melpómene, "su" Musa, Horacio le dedicó un nuevo himno en su IV libro de Odas.

En I-III hay una relación creciente que va de la amistad con las Piérides (cf. I, 26, 1: Musis amicus) al sacerdocio de las mismas (cf. III, 1, 3: Musarum sacerdos) en maduro y confiado respeto; sólo III, 4 mostró para este poemario una jubilosa entrega del poeta a sus queridas Musas, evidenciando una intimidad con ellas no alcanzada antes en su lírica y nacida - creemos - de una experiencia real, "d'une stupeur religieuse" (Lieberg, op. cit., p. 982) que forja entre el poeta y su "virgo patrona" un lazo inquebrantable con plena conciencia del poeta, tanto al poetizar como en el transcurso de su vida; IV, 3 arraiga ese vínculo en el día del nacimiento del poeta

Quem tu, Melpomene, semel nascentem placido lumine videris (v. 1-2)

haciendo resonar un eco calimaque 24 : el de la mirada complaciente y única al nacer el elegido, quien no se destacará por ninguna otra cosa, sino por el canto, y

23. Difieren los comentaristas en la atribución de "meritis" (v. 15); Villeneuve (op. cit., 1964, p. 148), entiende los de Horacio, lo mismo que V. Poeschl (Poeschl, 1970, p. 246-262) para quien el mérito de Horacio consiste en poner sobre su humilde patria el brillo de un princeps poético; Turolla (op. cit., $p$. 778) los de la Musa; no hay real oposición sino una transferencia: la poesía de Horacio no es sólo ars, sino ars más Ingenium, y este es fruto de la Musa; no tendría el poeta ningún mérito ni excelencia si no los debiera a sus Piérides y por eso a ella los remite, como también le deja librado a su voluntad el designio de coronarlo.

24. Calimaco: AITIA, frag. I, 37-8 (Pfeiffer, op. cit., p. 8) 
concretamente Horacio, el dilecto, por el "Aeolio carmine"; la perfección del vínculo incide en la perfección de la poesía reconocida ya sin envidia; aquel verbo "inseres" $(I, 1,35)$ en futuro ha devenido presente, Carmine saeculari mediante, nuestro venusino integra el canon de los líricos con que Roma lo ha enaltecido, y si en III,30 devolvía la excelencia poética, o sea su obra concreta, a su celestial protectora, aquí el lazo con ella es $\tan$ sintetizador que le reconoce toda su poesía como don que le pertenece y más aún, hasta el soplo que lo alienta en amorosa y filial entrega ${ }^{25}$

totum muneris hoc tui est (v. 21)

quod spiro et placeo, si placeo, tuum est. (v. 24)

Talía

Unica mención de esta musa en toda su poesía ubicada antes de IV, 8 ,

\section{Doctor argutae fidicen Thaliae}

su significación es problemática porque Horacio parece nutrirla de nuevos valores.

En general los comentaristas pasan por alto, como por sobre brasas ardientes, por este nombre; nadie discute la relación docente de Apolo con las Musas, pero ¿por qué Thalia, la "arguta", de voz aguda y armoniosa? También es una Gracia, pero el contexto nos induce a verla como una de las nueve hermanas.

En la Eg. VI de Virgilio (v. 2) aparece Thalia con una función de carácter pastoral, tal vez por inferencia vinculada a su etimología ${ }^{26}$, pero ese rasgo no se ajusta con el del himno a Apolo que es IV, 6.

Villeneuve (Villeneuve, 1964, p. 166) se escapa por la tangente señalando que Horacio la elige para designar las Musas en general, pero no dice el porqué; lo mismo observa Turolla (Turolla, 1963, p. 806).

G. Lieberg (op. cit., p. 965) plantea mejor la dificultad al relacionar Thalia con la "Daunia Camena" que es la misma poesía de Horacio, dependientes ambas de Apolo; a partir de esta estrofa Apolo es presentado como un dios músico que ha depuesto su espíritu vindicador volviéndose el garante de la paz augustea; Thalia sería el "symbole de cet heureux état"; siguiendo esta idea dirfamos que Thalia es un símbolo de la lírica civil de Horacio acuñado con una distintiva peculiaridad.

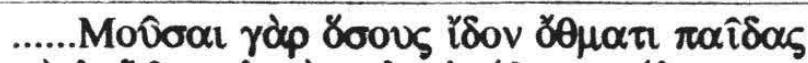

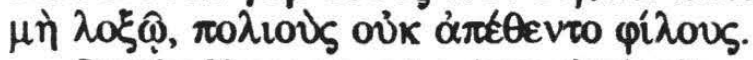

....... Pues las Musas a cuantos vieron siendo niños

con mirada no oblicua, canosos no los rechazaron como amigos.

25. Observar que IV, 8 está en el centro exacto de libro IV por lo que Melpómene resulta la imagen recapitulatoria por excelencia al igual que en I-III.

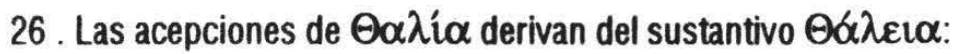

a) "vegetación"; como adjetivo "floreciente", "abundante"; en plural $\Theta \alpha \lambda \varepsilon \iota \alpha$ : "festín", por eso musa convivial y simposíaca; de la misma raíz tenemos $\theta \alpha \dot{\lambda} \lambda \varepsilon \alpha-\omega v$ (sólo en plural) "juego", "placer" que vincula a Talla con la familia de "Iusus", sinónimo de lírica amatoria lo cual no se da aqui. 


\section{Conclusion}

Destacamos en la mención individualizadora de algunas Musas, dentro de la adscripción del poeta a la gran tradición hesiódico-pindárica con inclusión de elementos alejandrinos, algunos rasgos típicamente horacianos: incorporación y equiparación de las Camenas ennianas con las Musas helénicas, su función mediadora entre Baco y Apolo, la dispensación de las especies Ilricas del "yenus tenue" (en la línea del ION platónico: 534c), la adaptación del ritmo eolio al "tarmen Latinum" y una relación personal e intima con todas las Musas, pero con una particular fillación con Melpómene, hecho único en la lírica grecolatina que hace del poeta un "vir musicalis", semejante analógicamente al vínculo con Mercurio, quien entre las divinidades masculinas lo constituye por su patronato en las diversas circunstancias de su vida en un "vir mercurialis" en esferas interrelacionadas.

Se podrá objetar que hay en Horacio un empleo retórico 27 y vaciado de contenido de las Musas, pero eso no ocurre cuando el poeta las invoca por su nombre y siendo estas menciones proporcionalmente escasas en 103 odas, ello indica la intención deliberada y la solicitud con que el poeta las ha elegido.

La relación de Horacio con las Musas, en particular con la suya, Melpómene, a la que añadimos con Mercurio, su protector, replantea el problema de su actitud religiosa con una convicción y un realismo que excede largamente a las consideraciones epicúreas y a las del llamado "aparato de dioses".

Coincidimos con G. Lieberg (op. cit. p. 984) - aunque él amplía su conclusión a las Musas nombradas en general - que en Horacio no se trata de ellas como "d'un processus de décadence, mais au contraire, d'un approfondissement considerable".

\section{Segunda Parte}

\section{La (s) Musa(s) innominada(s):}

Lo dicho para las Musas individualizadas por su nombre vale en general para la(s) Musa(s) innominada(s). Veamos si ésta(s) alcanza(n) algun otro rasgo distintivo en las odas donde su función es significativa.

Oda 1.6: Contiene la primera recusatio literaria de su colleción lírica; las victorias de Agripa serán cantadas al modo épico por Vario; Horacio no intentará ni

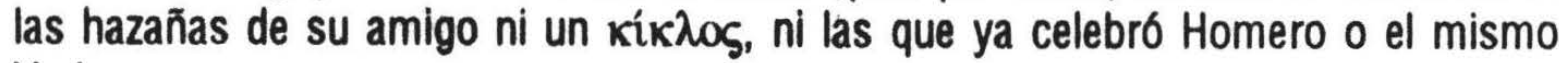
Vario

(nec) conamur, tenues grandia, dum pudor

inbellisque lyrae Musa potens velat

laudes egregii Caesaris et tuas

culpa deterere ingeni. 
Lo que Horacio descarta son los temas grandia (genus grande: tragedia y épica de la que aqui es cuestión); su inspiración y su ars poética son tenues (genus tenue: Irrica con todas sus especies); esta restriccion tiene dos fuentes:
a) su pudor que no le permite salirse de sus límites y es signo de su autoconciencia poética y
b) la Musa que rige una lira no guerrera.

Esta Musa que vetat o prohibe la épica es una impostación calimaquea del Apolo amonestador de los AITIA (Calimaco,frag. I, 21-24) que se renueva en la literatura augustea con frecuencia ${ }^{28}$ con el fin de encaminar al poeta dentro de un género, el lírico, como en I,6 y otras dentro de una especie genérica como en IV, 15.

Si Horacio individualiza la Musa, ésta casi no necesita atribuciones, el nombre está pleno de virtualidades y resulta una guia para que nos revele las mismas, en cambio si la Musa es genérica, se requieren calificaciones 0 determinantes que la precisen; por eso aqui el "inbellis lyrae potens" sintagma casi definido por el "inbellis" en oposición a un supuesto "bellica" confirmando el oxymoron "tenues grandia" desplegado en IV y V estrofa; la IV reitera contenidos épicos 0 grandia 29 , en cambio la $V$ despliega las especies líricas del genus tenue $(\lambda \varepsilon \pi \tau \alpha \lambda \varepsilon \eta)^{30}$
Nos convivia, nos proelia virginum sectis in iuvenes unguibus acrium cantamus, vacui sive quid urimur non praeter solitum leves.

fundamentalmente lírica individual de convivio y amatoria (con parodia de lenguaje épico: proelia); Horacio retoma con esta Musa inbellis al menos dos de las virtualidades implicitas en la Polyhymnia de I, $1,33$.

Sin embargo, el modo con que to hace y el contexto no tienen la solemnidad ni la vibración conmovedora de las menciones ya estudiadas, dando esta Musa la impresión de una metáfora retórica sobre las especies líricas.

Oda I, 26: Presenta otra modalidad de la plegaria a la Musa; en I,24 y en III,4 el poeta ruega a una Musa determinada que le conceda un canto "lugubris" 0

28. Cf. Virgilio, Eg. VI, 3-5; Horacio, Odas IV, 15,1-4; Propercio, El. III, 3; en 8át. 1, 10, 31-35 Apolo es sustituido por Quirino quien se aparece en sueños al poeta prohibiendole escribir poesia en griego.

Tema muy desarrollado por Walter Wimmel (Wimmel, 1960) y A. Kambylis (Kambylis, 1965).

29 La recusatio consiste en declarar, no sin alguna ironia que no cantará temas que si enumera aunque sin desplegar, para luego desecharlos por los que realmente desarrollará.

30 En la primera recusatio lírica Horacio propone una distinción muy amplia entre lirica y épica al modo como en Sát. I, 4 ha enfrentado sátira y genera maiora (épica y tragedia), a medida que avanzamos en las siguientes recusationes "the most significant tension is the contrast between lyric an heroic lyric" (Cf. Smith, P., 1968, p. 62), dicho de otro modo entre lírica individual y civil, siendo ésta tal vez el logro más original y romano de Horacio; "IV, 15 is the only poem of this type in which there is not tension between plublic heroism and the private ego; here in fact, the Pax Augusta replace Horace's private personality as the antithesis of brash heroism" ( Smith, P op. cit. p 63I) 
"Iongum" y después de esta petición se despliega el carmen como expresado por la divinidad.

En cambio, en 1,6 al impedir la Musa el canto épico, tampoco hay lugar para uno lírico, sino el anuncio de 10 que ella veta o permite; en I,26 y en I,32 tenemos el requerimiento a la Piplea 0 al "barbiton" sin incluir el poema que es objeto de esa plegaria (cf. Kilpatrick, 1969, p.215-39).

Después de I.1; I.12 y I.24 la amistad de Horacio con las Musas es previsible, pero llega de un modo conmovedor la simplicidad de la expresión conque se abre la oda

\section{Musis amicus... (v. 1)}

El Movoópitos no es ajeno a la poesia épica y lirica de los griegos (cf. Homero, Odisea VIII, 63; Hesíodo, Theog. 96; Calímaco, AITIA, frag. I, 37; Teócrito I, 141) como tampoco de la latina; Virgilio dirá después en En. IX, 774 "amicum...musis", porque la amistad entre dioses y hombres es un rasgo connatural al mundo grecoromano; por alli a Hesíodo (Theog. 100) se le escapará

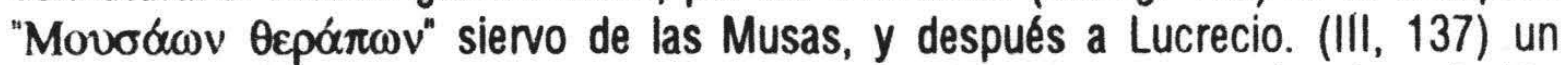
"Heliconiadum comites", pero sólo Horacio evidencia ese grado de relación entrañable entre la $\varphi \imath \lambda i \alpha(v$. 1) y la filialidad de IV, 3, unido al vates como "sacerdos Musarum" (III,1).

El amigo de las Musas puede arrojar al capricho del mar y los vientos sus miedos y aflicciones, porque la amistad con la Musa lo libera de las ansiedades superficiales, no del dolor, sino de lo que hace a las preocupaciones adventicias que atormentan o llenan el alma; el poeta es el único verdaderamente inmune y securus (sin preocupaciones), atento sólo a lo esencial y por eso puede reclamar lo esencial: que la dulce Piplea entreteja una corona para su amigo Lamia, es decir, un poema. Horacio no podria alabar a su amigo sin el don de la Musa, ya que

Piplea dulcis. Nil sine te mei

prosunt honoris; hunc fidibus nobis,

hunc Lesbio sacrare plectro

teque tuasque decet sorores. (v.9-12)

Los v. 9-10 evocan I, 1, 29-34 y anticipan III. 30 y IV, 8 en dos rasgos: 1) no hay ars sin ingenium como don de la Musa por lo que sin ella nada seria la gloria que Horacio podria conferir a Lamia 31 y 2) esta honra la Musa concede a través de su portav0z, Horacio, con "fidibus novis" 32 ; asi se cierra el ciclo con una estructura anular, donde lo que habia nacido de la Musa, vuelve a ella en evidente reconocimiento despuěs de la consagración (Sacrare) publica del homenajeado y de Horacio por añadidura.

31. Sine te: La locución es previsible y usual en himnos y textos religiosos ( cf. Nisbet, 1970, p. 307).

32. Fidibus novis: El atributo puede aunar dos valores: a) la novedad de la pureza, ya que Musa se goza con las "fontibus integris "y su corona, es decir el poema, se entrelaza con flores intocadas (poema de la Musa que es poema de Horacio); b) con cuerdas romanas dentro de la especie lírica del encomio acuñada por el "Lesbio plectro" con que Horacio celebrará tanto a Lamia como a su Piplea y restantes hermanas. 
Oda II. 1: Dirigida a Asinto Polión, poeta trágico e historiador de guerra civil, contiene una nueva recusatio del tema épico con una derivación más compleja.

Horacio pone en estrofa alcaica una breve referencia al multifacético material de la guerra civil historiado por Polión en diecisiete libros que la Antigüedad conocio; Horacio apunta a las causas de la guerra, a sus imponderables y a los hechos principales, lo cual podria encuadrarse en modo épico, pero la história con su glorificación de los héroes da una salida pedestre, o sea, en prosa a la celebracion y ordenamiento de las gestas. El resto de la Oda se va en desplegar el proceso de la guerra civil, pero al modo del lirismo heróico con ritmo alcaico, el más adecuado por su vivida movilidade para la $\beta \alpha \sigma \iota \lambda \iota k \alpha \grave{\alpha} \mu \hat{\varepsilon} \lambda \eta$.

En v. 9 hay una referencia retórica a la "severae Musa tragoediae" momentáneamente abandonada por el autor y cuando se llega al climax de la penúltima estrofa (v. 33-36) con las matanzas fratricidas que tiñeron en una hipérbole, mares y riberas sin limites, se vuelve, en un anticlimax a

Sed ne relictis, Musa provax, iocis

Ceae retractes munera neniae, mecum Dionaeo sub antro quaere modos leviore plectro

porque el poeta con el recurso de la litote ha cantado la que dice que no dice que no va a cantar y debe volver al nivel del lirismo individual: en contraposición a la Musa severa se apela a la Musa procax, con oposición de atributos, reelaboración del "tenues grandia" de I,6.

La Musa procax (atrevida, sin contención, jocosa) ha dejado de lado su temática propia amaloria o convivial en el "relictis locis" y por excedida ha tentado con impropia ambiqüedad el estilo patético o v́ $\psi \eta \lambda o ́ v$ en el que Simónides de Ceos era el paradigma; el verbo "retractes" implica una repetición que es también un rasgo de la nenia o $\theta p \hat{v}$ vos en la reiteración de expresiones dolorosas.

En I,6 Horacio con más cortedad presenta una Musa prohibitiva. en II,1 en cambio, el velo parte del mismo poeta a lo que se sigue una invitación más audaz: que la Musa comparta con el vate el alumbramiento de ritmos más ligeros (leviore plectro), propios del genue tenue o leve 33 .

En suma II,1 sigue desplegando la Musa inbellis de 1,6 por descarte de las variantes en verso o prosa del genus grande.

Oda II,10: La oda de la aurea mediocritas muestra en su V estrofa (v. 17$20)$ los vaivenes de la vida humana en una $\gamma \omega \omega \mu \eta \eta$ sobre la inestabilidade de bienes y males, desarollada de inmediato con un bellisima imagen:

\author{
....Non, si male nunc, el olim \\ sic erit: quondam cithera tacentem \\ suscitat Musa neque semper arcum \\ tendit Apolo.
}

33. En otra comunicación ( Buisel, M. D. , 1987) examiné los valores de "Dionaeo "; tanto Horacio como Virgilio prefieren la versión homérica y la hesiódica sobre la ascendencia de Afrodita; el mito de la castración de Saturno es demasiado bárbaro para el linaje pede la madre de la gens Julia, por lo que "Dionaeo" se carga de una connotación civil que excede a la del solo lirismo individual erótico y anticipa el tratamiento maternal de Venus, Enneadum genitrix. 
Apolo terrible como dios arquero, en correlación con "male nunc" no siempre mantiene postura guerrera, a veces la declina (non...et olim sic erit) y cuando esto ocurre la musica lo invade todo, porque el ha despertado a la Musa duermiente y silenciosa.

La mayoria de los comentaristas y editores ${ }^{34}$ hacen a Musa sinónimo de música; creemos por el contrario que Musa es aqui "an external mithological personage" (Nisbet, op.cit, II, p.164) o dicho con menos tecnicismo y frialdad una de las nueve hermanas o la Musa en sentido absoluto, profunda e intimamente ligada a Apolo su maestro, que canta y actua cundo su señor depone el arco; este texto es el único de los referidos a las Musas en donde se amplia el simbolismo de ambos dioses, pasando a representar Apolo una situación desdichada, y la Musa una propicia: por otra parte, el equilibrio de las imágenes opuestas con las que se articula el poema reclama a la Musa como divindad: incluso, si ni la consideramos como dea, la imagem pierde vigor, belleza y su arrebatador encanto personal.

Oda 11,12: En la serie de las recusationes con litote reitera con leves variantes a II,1 ahora dirigida a Mecenas; la citara horaciana con sus "mollibus modis" no se adecua al tratamento épico de la guerra ni mítica; la gesta augustea se ajusta a las "pedestribus historiis" de Mecenas; la dulcis Musa le requiere el elogio de Licymnia, la esposa bella, fiel y por demás encantadora de Mecenas; anunque la alabanza de la propia amada, y no la de esposa ajena, sea lo usual de la lírica amorosa.

Oda II, 16: Compuesta sobre la polaridad otium-negotium que cada tipo humano comprende a su manera como variaciones de un significado básico; el otium del poeta consiste en un estado de paz y reposo apto para la contemplación, la sabiduria y la creación artistica; el poeta no puede ni debe ambicionar las posesiones materiales ni los honores sociales, porque

vivitur pavo bene (v.13)

los bienes de su posesión están representados en un salero heredado y solitario que brilla en su "mensa tenuis" (v.14), símbolo y correlación de un vita tenuis y de una Musa tenuis.

Grospho representa una posesion legitima de bienes materiales bien empleados, pero ésa no es la medida del poeta que ha recibido la marca de la Musa como una elección del destino. En efecto la Camena aparece aqui subordinada al fatum que es quien le asigna la Musa

mihi parva rura et

spiritum Graiae tenuem Camenae

Parca non mendax dedit et malignun

spernere volgus. (v. 37-40)

34. Villeneuve (Villeneuve, 1964, p. 70), Turolla (Turolla, 1963, p. 616) e incluso Nisbet (op. cit, 1978, p. 164-5) - éste último siguiendo a Bentley-tienden a interpretar Musa como metonimia por másica; Bo (Bo, 1966, I.II, p.62-3) la coloca como dea; nada dicen de este texto ni E Fraenkel, ni G. Lieberg ni G. Pasquali. 
Fatum personalizado en una Parca veraz, cuyas previsiones no engañan, son siempre veridicas ("Car, saec., v. 25 veraces Parcae") y dada esta veracidad el poeta recibe tres dones incontrastables en perfecta concordancia; la pequeña posesion de su finca, el desprecio del vulgo malicioso y lleno de envidia (cf. I,1,32 y III, 1, 1) y fundamentalmente la poesia como aliento de raigambre holénica, pero recortado por el adjetivo "tenue" que no trace solo a la levedad del soplo, sino a la poesia lírica $0 \gamma \varepsilon \hat{\varepsilon}$ os $\lambda \varepsilon \pi \tau o ́ v$ concedida por la Camena griega (cf. Calabrae Pierides en IV 8,20 ) contraste deliberado para asociar a la donante y al donado ${ }^{35}$.

Oda III.1: La primera de las Odas romanas se abre con una estrofa proemio para el poemario y para el libro III; alli Horacio ha crecido en su relación con las Musas pasando de la amistad con ellas a su sacerdocio. No se trata de una ceremonia litúrgica real, sino de una transposición de la misma a otro plano, elevado si, pero distinto, donde el "Musarum sacerdos" (v.3), intermediario e intérprete único de las Musas hará resonar "carmina non prius audita" (v.2-3), carmina que son revelaciones de lo que las Musas quieren que el poeta diga con contenido civico: aqui Horacio como vates es no sólo mediador, sino también portavoz de una nueva realidad política promovida por sus olimpicas protectoras.

Oda III,3: Culmina con el discurso de Juno, advertencia para los romanos de no intentar la reconstrucción de Troya (tema análogo En.12, 819-828); en estrofa alcaica tiene una tonalidad épica indiscutible y es uno de los tantos ejemplos donde el lirismo de Horacio se vuelve fronterizo con un genus maior 0 alcanza los limites del estilo sublime. El poeta siente ese non plus ultra y por eso cierra el texto con un anticlimax ya empleado en $I I, 1$ que tiene mucho de final imprevisible 0

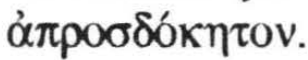

Non hoc iocosae conveniet lyrae; quo, Musa, tendis? Desinet pervicax

referre sermoni deorum et

magna modis tenuare parvis; (v.69-72)

La lira jocosa es la del genus tenue: el hoc se refiere al discurso épico de Juno, evidentemente parece haber una extrapolación a las que Horacio con sus lítotes nos tiene acostumbrados: no hará épica, pero casi la hace en endecasílabos y no en hexámetros; el rechazo de este ritmo es lo que lo mantiene en las riberas de la lírica; pero no es él quien se extralimita, es su querida Musa, obstinada en revelarle los secretos designios de los dioses para sus conciudadanos, por eso el poeta con una orden entre respetuosa y ingenua (cf. II, 1) la exhorta a "tenuare", o sea a volver al lirismo sutilizando y aligerando los grandes temas con ritmos más pequeños.

Pero después de todo, pese a la nueva recusatio, Horacio ha referido, como portavoz de la Musa, los arcanos de Juno sin llegar al epos, dentro del lirismo heroico o sublime.

Cabe preguntarse cuáles son las fronteras del genus tenue horaciano; el I,6 no pasaba de lo convivial y amatorio, pero desde I,1 a III, 30 la gama de su lírica

35. H. J. Mette, 1961, p. 220-4) señala que la "mensa tenuis" propia de una vita parva tiene su forma acabada en el genus tenue como marca de un gran artista que ha entretejido el estilo literario con el estilo de vida en una sola realidad 
resulta amplisima ${ }^{36}$. En realidad Horacio rompe los moldes latinos del genus tenue para llevarlos a una plenitud no usual: la del lirismo heroico y civico ${ }^{37}$. Lo cierto es que entonces la Musa no se extrapoló y menos él, pero hicieron crecer y adensar un territorio lirico hasta entonces virginal.

De alli que la "regina Caliope" de III,4 sea seguramente el nombre de la Musa "pervicax" con que se cierra III, 3 y que prodiga en la oda siguiente otra operacion divina: la Titanomaquia.

La recusatio más que un problema real no deja de ser un topos literario con el que Horacio juega dominándolo con sin igual maestria y con la ironia del viejo satirista que sabe perfectamente hasta dónde puede llegar.

Oda IV, 8: En asclepiadeos menores como I,1 y III, 30 presenta otro elemento del processo creativo menos explicito en I-III, referido a la inmortalidad conferida al poeta. En IV.6, 29-30

\section{Spiritum Phoebus mihi, Phoebus artem \\ Carminis nomen que dedit poetas.}

recoge sintéticamente el spiritum de I,1, - alli más dionisíaco que apolíneo como aqui -, el artem carminis ${ }^{38}$, perfecta elaboración de las odas, y el nomen poetae, renombre o fama, pero ¿cómo entender el genitivo poetae? Queda flotando una tranquila ambigüidad: a) es la fama alcanzada por la propia poesia $y / 0$ b) es la alcanzada por otro enaltecido por el poeta. Se trata de ambas realidades aunque con una se apunta a I-III y la otra al libro IV. En suma, todo es don de Apolo. No hay duda que en IV, 3 el don de la Piéride otorga un renombre sin fin al propio Horacio, pero en IV, 8 y 9 son las acciones humanas inmortalizadas por los poetas, las que enlazan su gloria con las del cantor.

El mito no seria mito (Eaco o Rómulo) y el vencedor de Cartago no tendria vida si los poetas (Homero o Ennio) por encima del mármol, no los hubieran glorificado con la épica, pero Horacio va más lejos aún con esta oda clave y pilar del libro IV: la Musa no sólo elige al poeta, lo inspira, lo posee y lo hace su amigo y sacerdote, sino que al impedir con la palabra poética que muera el hombre de valor, le confiere en el cielo un grado de beatitud análogo al del status heróico

\section{Dignum laude virum Musa velat mori, caelo Musa beat. (v.28-29)}

que tenien Hercules, Castor y Pólux o Baco, por ser con su doble púors hilos de dios mortal, esto les aseguraba en la tradición greco-latino la apoteosis.

Por su filiación con la Musa que lo miro al nacer por designio de la Parca, Horacio extrema las consecuencias de ese vínculo no sólo para él sino también para los por el cantados: Censorino en IV, 8 y Lollio en IV, 9.

36 . J. Granarollo (Granarollo, 1971) plantea un problema semejante en Catulo: el concepto de nugae del c. I ¿abarca también los carmina docta de su nuevo éríl $u$ vov mitico?

37 . Cf. D. Garrison (Garrison, 1979, p. 40-4).

38 . Entendiendo el genitivo carminis no sólo como canto en general, sino con mayor especificidad, por la colección de Odas (Carmina) I-III 
Ningún poeta augusteo fue más lejos en su lirismo en la indagación del processo creador que Horacio, quien con su filiación adoptiva, puramente espiritual, pero no por eso menos concreta, logra un grado de beatitud que lo exime del

\section{Pulvis et umbra sumus (IV, 7,16$)$}

de lo cual ni Eneas estaria exento si no fuera por Virgilio ${ }^{39}$.

En I-III Horacio inmortaliza $\kappa \alpha \tau \grave{\alpha} \lambda \varepsilon \pi \tau o ́ v$ a la fuente de Bandusia (III,13): hata IV, 8 es la hazaña heroica referida por Homero y Ennio o biene posibilidades celebratorias el poeta que pindarice (IV, 2), pero en IV, 9 Horacio afina con una última sutileza el don de Melpómene la moduladora: la Musa épica no es la unica dispensadora de gloria, la de Pindaro y la de los liricos griegos también lo han logrado, pero en Roma el que nació junto al Aufido enlazó voz y música de lira y flauta con un arte antes ignoto y con su lírica nueva ganó la inmorialidad para si, sus amigos y para la aetas pacificada por Augusto

Ne forte credas interitura quae

longe sonantem natus ad Aufidum

non ante volgata per artis

verba loquor socianda chordis. (v. 1-4)

\section{Bibliografia}

BO, D. Lexicon Horatianum. Hildesheim: G. Olms, 1966, T. I y II.

BOYAnCE, P. Le culte des Muses chez les philosophes grecs. Paris: Bocard, 1937.

BoYancE, P. Grandeur d'Horace. Bull. de l'Ass. G. Budé, 1955, p. 48-64.

BUECHNER, K. Horace et Epicure. Actes du VIlleme Congrès, Ass. G. Budé. Paris: Les Belles Lettres, 1968, p. 457-469.

BUECHNER, K. II musico in Orazio. Atti del III Convegno di Studio. Roma: Centro Internazionale di Studi Oraziani, 1970.

BUISEL, M. D. La divinidad de Baco en la lirica horaciana. Actas de la V Reuniâo Anual de la S. B. E. C., Garibaldi, 1990.

BUISEL, M. D. La sátira horaciana como "genus" literario. Comunicación para el XII Simp. Nac. de Est. Clásicos, Córdoba, 1992.

BUISEL, M. D. La divindad de Venus en la lirica horaciana. Comunicación para las Jornadas de Est. Clas de la UCA, 1987.

39. La Oda IV, 7 no puede leerse aislada, debe integrarse, por to menos con IV, 8 y 9 , con las que constituye una trilogia para completar su significación. Mérito de E. Fraenkel (Fraenkel, 1966, p. 421-3) y de Dag Norberg (Norberg, 1952, p. 95-107) es haber destacado el encadenamiento semántico. 
CONNOR, P. The actual quality of experience: and appraisal of the nature of Horace's odes. A. N. R. W., B. 31, 3, Berlin, W. de Gruyter, 1981, p. 16121639.

CREMONA, W. La poesia civile di Orazio. Milano: Vita e Pensiero, 1982.

FRAENKEL, E. Horace. Oxford Clarendon Press, 1966.

GARRISON, D. Quo Musa tendis? Horace's Augustam Patriotism, The Classical Bulletin 55, 1979, p. 40-4.

granarollo, J. D'Ennius a Catulle, Paris, Les Belles Lettres, 1971.

KAMBYLIS. A. Die Dichterweihe und Ihre Symbolik, Heidelberg, Winter, 1965.

KIESSLING, A, HEINZE, R., BURCK, E. Horaz. Berlin: Weidmann, 1958, B. I-III.

KILPATRICK, R. Two horatian poems. C. I,26 and I,32, Yale, Cl. St. 21, 1969, p. 215-39.

LIEBERG, G. Horace et les Muses. Latomus XXXVI, 4 1977, p. 962-988.

METTE, H. J. "Genus Tenue" und "Mensa Tenuis" Bei Horaz, en Wege zu Horaz, Darmstadt, Wissenschaftliche Buchgessellsschaft, 1961, p. 220-4.

NISBET, R., HUBBARD, M. A commentary on Horace odes. T. I, Oxford Clarendon Press, 1970; T. II, 1978.

NORBERG, D. Le Quatrième LIvre des Odes D'Horace, Emerita XX, 1952, p. 95-107.

OPPERMANN, H. Das Goettliche im Spiegel der Dichtung der Horaz. En Wege zu Horaz, Darmstadt, Wissenschaftliche Buchgesselschaft, 1972, p. 167-182.

0TTO, W. Las Musas. Buenos Aires: Eudeba, 1981.

PASQUALI, G. Orazio Lirico, Firenze, Le Monnier, 1966.

PFEIFFER, R. Callimachos. Oxford Clarendon Press, Vol. I, 1949; Vol. II, 1953.

POESCHL, V. Horazische Lirik. Heildelberg: Winter, 1970; III, 30, p. 246-262.

RACE, W. The classical "priamel" from Homer to Boethius. Leiden: Brill, 1982.

SINDIKUS, H. P. Die Lyryk des Horaz, Darmstadt, Wissenschaftliche Buchgessellschaft, B. I, 1989, B. II, 1990.

SMITH, P. Poetic Tensions in the Horacian "Recusatio", Am. J. Ph. 89, 1968, p. 56-65.

TUROLLA, E. Orazio. Le opere. Torino: Loescher, 1963.

VILLENEUVE, F. Horace. Paris: Les Belles Lettres; Odes, 1964; Satires, 1966.

WIMMEL, W. Kallimachos in Rom, Wiesbaden, Hermes, 1960.

WITKE, Ch. Horace's roman odes. Leiden: Brill, 1983. 